\section{CHARITY FUN DAY BBO}

The Anglo-Asian Odontological Group (AOG) would like to offer its members a resounding 'Aaa-Ooo-Gee' ('Welcome') to its Summer BBQ and Family Day, which will take place from midday on Sunday 10 July 2011 at Haberdashers' Aske's Girl's School, Butterfly Lane, Elstree, Hertfordshire WD6 3BT.

This light-hearted event is an ideal opportunity for dentists and their families to socialise in a welcoming and comfortable environment. Three hundred guests attended the Summer BBQ last year, attracted not only by the chance to mingle but also the music, family sports, children's entertainment and excellent food and drink on offer.
Pay-on-the-day entry to the Summer BBQ is $£ 10$ for adults and $£ 2$ for children, but booking in advance means that adults pay $£ 5$ and children only $£ 1$. Book online in advance for discount savings.

All proceeds from this event, as with all AOG events, go towards one of its many charitable worldwide projects. The most recent projects are in India, Sri Lanka and Tanzania.

Exclusive entry for AOG members and their families to this and other events is just one of the many benefits of joining this distinguished group, which can also help you reduce your outgoings on such products and services as dental equipment and educational courses.

Reader response number 60

\title{
ULTRAFINE INTERDENTAL BRUSHES TO SUIT ALL PATIENTS
}

Oral healthcare specialists Curaprox have devised a range of ultrafine interdental brushes that match each interproximal space. The soft brushes are gentle on the most delicate of gums and are available in a variety of lengths and thicknesses, ensuring perfect compatibility for every patient.

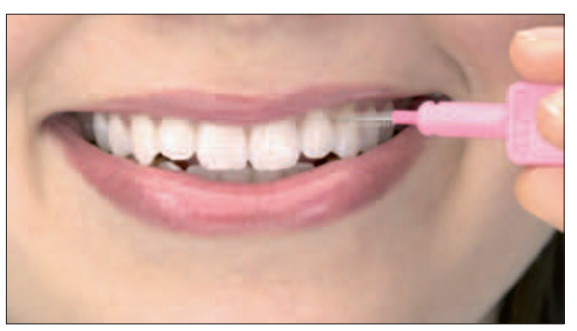

\section{A MUST-HAVE PRODUCT}

Dentist's Choice Gum \& Whitening Expert toothpaste from Beverly Hills Formula boasts a unique gum protection system consisting of vitamin $E$ to invigorate and strengthen the gums, fluoride to protect the exposed root area, Permethol to help reduce and stop bleeding gums, desensitising agent potassium citrate to quickly and effectively block the transmission of pain, whilst panthenol, Q10 and folic acid all
Patients can effortlessly incorporate interproximal cleaning into a daily oral healthcare routine. Interdental brushes are much easier to employ than dental floss, successfully cleaning debris away from areas that are difficult to reach.

Studies looking at gum disease have concluded that an effective oral healthcare routine could help patients to avoid experiencing stillbirths or developing breast cancer. Such findings corroborate the widely accepted belief amongst healthcare professionals of a systemic link between gum disease and chronic disorders found beyond the oral cavity. Reader response number 61

help promote healthy growth of the gum tissues.

Removing stains in just one minute this new toothpaste is also proven to be less abrasive when compared with other leading brands of both whitening and regular toothpaste.

The launch of Dentist's Choice Gum A Whitening Expert toothpaste is further proof that the Beverly Hills Formula brand has evolved into a must-have product for today's aesthetic-conscious patient.

Reader response number 62

\section{DENTAL FURNITURE AND EQUIPMENT}

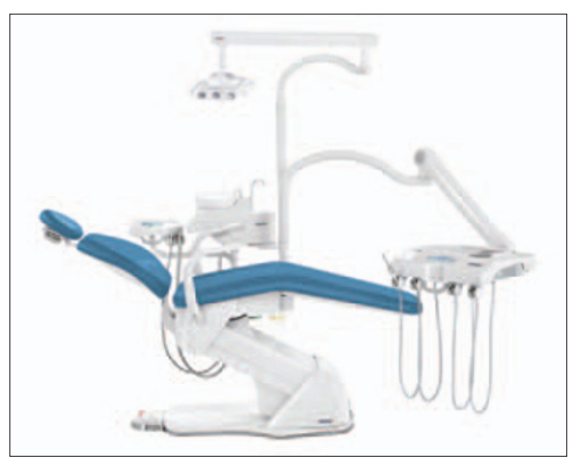

Plinth 2000 of Suffolk, leading UK manufacturer of medical-grade treatment couches and chairs, is diversifying into another healthcare sector, following a distribution agreement with one of the world's largest producers of dental furniture and equipment, Gnatus of Sao Paolo, Brazil. Under the arrangement, Plinth will market and supply Gnatus dental sets, dental chairs, water units, $\mathrm{X}$-ray equipment, handpieces and accessories in the UK, Ireland, Belgium and the Netherlands, through a newly-created specialist division, Plinth Dental.

Plinth Dental will focus initially on marketing the top-line Syncrus HLX Full dental set and the budget-priced POP Star LSF dental set, together with a full range of handpieces and accessories. There will also be prophylaxis equipment, like the ultrasonic Jet Sonic BP Scaler, and compact autoclaves, including the latest stainless steel model, as well as heightadjustable stools with anatomical backrests, all designed with the needs of the dental profession in mind.

At its Stowmarket, Suffolk headquarters, Plinth will hold selected dental chairs, stools and dental sets in stock for immediate availability, although delivery times across all other Gnatus products from Brazil will be just 4-6 weeks. The UK partner will use its treatment couch production experience to custom fit any of the dozen different Gnatus upholstery colours and its staff are being factory trained to carry out minor repairs and maintenance, with annual service recommended for such highly engineered equipment. A 2-year warranty for dental chairs and one year's cover for handpieces will be offered as standard.

Reader response number 63 